\title{
RELEVANT FACTORS FOR THE SUSPENSION OF THE PAYMENT OF DISPUTED TAX - A COMPARATIVE
}

\section{ANALYSIS}

\author{
Linda van Zy|* \\ Stellenbosch University
}

Received: October 2015

\author{
Danielle van Wyk" \\ Stellenbosch University
}

Accepted: February 2016

\begin{abstract}
Section 164(3) of the Tax Administration Act No. 28 of 2011 gives a senior SARS official the discretion to suspend the payment of disputed tax or a portion thereof, having regard to relevant factors. Limited guidance is available in this regard. The objectives are to establish the concerns and uncertainties regarding the relevant factors and to determine whether a 'suspension of the payment of disputed tax' in terms of section 164(3) constitutes the granting of 'credit' in terms of a 'credit agreement' in terms of the National Credit Act, Act No. 34 of 2005. This is achieved by adopting an explanatory research approach and performing a literature review and comparative analysis respectively. The conclusion is reached that the current factors listed are not necessarily the most relevant ones. Recommendations are made to simplify the process and to revise and improve the wording regarding the relevant factors.
\end{abstract}

Keywords

Section 164(3) of the Tax Administration Act No. 28 of 2011, National Credit Act, Act No. 34 of 2005, request, suspend, relevant factors, defer, payment, credit

*Prof $\mathbf{L}$ van $\mathbf{Z y l}$ is an associate professor in the School of Accountancy, Stellenbosch University, South Africa. [Ivanschalk@sun.ac.za]

*Mrs D van Wyk is a lecturer in the School of Accountancy, Stellenbosch University, South Africa. 


\section{INTRODUCTION}

Taxpayers registered with the South African Revenue Service ('the SARS') are obliged to pay their tax liability according to their tax assessment (Short Guide to the Tax Administration Act, 2011, 2013:58). This liability to pay exists notwithstanding an objection lodged by the taxpayer. Section 164 of the Tax Administration Act No. 28 of 2011 ('the Tax Administration Act'), which regulates the payment of tax pending an objection or appeal, replaced section 88 of the Income Tax Act 58 of 1962 ('Income Tax Act') and section 36 of the Value-Added Tax Act 89 of 1991 ('VAT Act') in 2012.

Section 164(1) of the Tax Administration Act states that

Unless a senior SARS official otherwise directs in terms of subsection (3) -

(a) the obligation to pay tax; and

(b) the right of SARS to receive and recover tax,

will not be suspended by an objection or appeal or pending the decision of a court of law pursuant to an appeal under section 133.

This subsection is also known as the 'pay now, argue later' rule (Short Guide to the Tax Administration Act, 2011, 2013:58). It requires taxpayers to pay the SARS on assessment first before pursuing their various remedies against the SARS (Dachs, 2014:10). Section 164(2) of the Tax Administration Act allows taxpayers to make a request to a senior SARS official to suspend the payment of tax, or a portion thereof, due under an assessment if the taxpayers intend to dispute the liability to pay such tax under Chapter 9 of the Tax Administration Act. Unfortunately the Tax Administration Act provides no guidance on the process to be followed, the form or the contents of such a request. The SARS's website has, however, been updated in April 2015 to include some detail in respect of the administrative aspects regarding a request in terms of section 164(2) of the Tax Administration Act.

Section 164(3) of the Tax Administration Act ('section 164(3)') lists the factors to be considered by the senior SARS official when adjudicating a request to suspend the payment of disputed tax and currently determines that:

A senior SARS official may suspend payment of the disputed tax or a portion thereof having regard to relevant factors, including -

(a) whether the recovery of the disputed tax will be in jeopardy or there will be a risk of dissipation of assets;

(b) the compliance history of the taxpayer with SARS;

(c) whether fraud is prima facie involved in the origin of the dispute;

(d) whether payment will result in irreparable hardship to the taxpayer not justified by the prejudice to SARS or the fiscus if the disputed tax is not paid or recovered; or

(e) whether the taxpayer has tendered adequate security for the payment ofthe disputed tax and accepting it is in the interest of SARS or the fiscus. 
Although section 164(3) specifies five relevant factors to be considered, various academic writers and industry experts raised concerns and uncertainties regarding these factors which included inter alia, the concern that the relevance of some of the factors is unclear (Williams, 2012:6). To 'suspend' a payment in terms of section 164 (3) could be similar to 'defer' a 'credit'. The provisions in the National Credit Act, Act 34 of 2005 ('NCA') regarding the granting of 'credit' (as defined), might therefore provide guidance regarding the possible simplification of the relevant factors and the process in terms of section 164(3), and are investigated.

\section{RESEARCH OBJECTIVE, RESEARCH METHODOLOGY, SCOPE AND VALUE OF RESEARCH}

The SARS provides limited guidelines in respect of the administrative aspects of the request process. However, no guidelines regarding the factors to be considered are provided and the relevance of some of the factors is questionable. These uncertainties negatively affect taxpayers who want to submit a request for the suspension of the payment of disputed tax.

The first objective of this article is to establish the concerns and uncertainties regarding the relevant factors listed in section 164(3) ('the relevant factors'). A second objective is to determine whether the 'suspension of the payment of disputed tax' in terms of section 164(3) constitute the granting of 'credit' in terms of the NCA. If so, it must be established whether the factors taken into account and the process followed by the NCA when granting a request for credit can provide any guidance regarding the relevance of the specified relevant factors and the process in terms of section 164(3).

The research approach adopted to meet the two objectives is explanatory research. The research method adopted firstly consists of a literature review to critically evaluate the relevant factors. The literature review includes relevant articles by academics and industry experts. South African legislation and case law are also analysed. The scope of the research is therefore limited, and only pertains to a South African context. An international comparison, which can possibly provide additional recommendations and can contribute to improve the process, will be considered in future studies.

Secondly, a comparative analysis is done between the relevant factors and the process in respect of a request for the suspension of the payment of disputed tax and the factors and the process applicable to the granting of 'credit' in terms of the NCA. This is done to establish whether the current relevant factors are the most relevant factors, and to identify other possible enhancements, which can simplify the process of a request for the suspension of the payment of disputed tax.

The research was done in order to assist taxpayers by creating an awareness regarding the pitfalls surrounding the relevant factors. This article provides clarity regarding the remaining uncertainties in respect of the relevant factors and questions the relevance of some of the relevant factors. The contribution of this article is to make recommendations in order to simplify the process and improve the wording regarding some of the relevant factors. This will assist taxpayers with their requests for the suspension of the payment of disputed tax, and could facilitate the process regarding future requests for suspension of disputed tax by taxpayers while simultaneously endorsing the SARS' focus on low risk revenue collection. 


\section{ANALYSIS OF THE RELEVANT FACTORS}

\subsection{Introduction}

When considering whether or not to submit a request for the suspension of the payment of disputed tax, taxpayers must be aware of the relevant factors. The senior SARS official will take these factors into account to decide whether or not to grant the request (section 164(3)). A number of academic writers and industry experts have raised some concerns and uncertainties regarding the relevant factors since their introduction into legislation (Dachs, $P$ (2014), Kotze, D (2015), Kruger, L (2014), PWC South Africa (2015), Rood, L (2009), Solomon, T (2015), Treurnicht, M (2015), Williams, R.C. (2012)). Where relevant, amendments to the relevant factors since first enactment will be highlighted. By examining these concerns and uncertainties this section aims to determine whether the relevant factors listed in the latest version of the Tax Administration Act are indeed the most relevant and applicable ones to consider in respect of such a request.

\subsection{Analysis of the concerns and uncertainties regarding the relevant factors}

The phrase '...relevant factors, including -' was only added to the opening sentence of section 164(3) by section 50(1) of the Tax Administration Laws Amendment Act 44 of 2014 ('TALA'). This amendment resolved an initial concern regarding the specified relevant factors, namely whether the list of factors was meant to be exhaustive or not. After the amendment, PWC South Africa (2015:4) also confirmed that the section no longer sets out a closed list of relevant factors, that the list is not exhaustive and that the variety of relevant factors is now unlimited.

\subsection{1 (a) whether the recovery of the disputed tax will be in jeopardy or there will be a risk of dissipation of assets;}

The word 'jeopardy' is not defined in the Tax Administration Act and section 164 does not explain the circumstances when the recovery of disputed tax will be in jeopardy (Solomon, 2015:par.8). According to the Oxford English Dictionary ('OED') (2015), 'jeopardy' means, among others, 'a risk of loss'. It must therefore be determined whether there is a risk that SARS will be unable to recover the disputed tax from the taxpayer. Solomon (2015:par.8) is of the opinion that this factor can easily be dealt with, if it can be verified that no risk with regards to collection exist. It is suggested that this verification can possibly be obtained from a credit risk analysis of the taxpayer.

It however seems that, based on the SARS's powerful collection procedures and policies in terms of the South African Revenue Service Act, 34 of 1997 and the Tax Administration Act, the chances are really slim that the SARS will be unable to collect the tax amount, or at least a portion thereof. It is therefore questioned whether this part of the factor is really relevant when considering a request for the suspension of disputed tax. One should, however, take note that section 164(6) of the Tax Administration Act prohibits the SARS from taking steps to recover the tax during the period between the receipt of a suspension request and ten business days after notice of the SARS' decision regarding the suspension has been issued to the taxpayer. This prohibition is not applicable if the SARS has a reasonable belief that there is a risk of dissipation of assets by the taxpayer concerned. It is uncertain what is meant by 'reasonable belief' and also how the SARS is going to apply this subjective judgment in a consistent manner. 
'Dissipation of assets' is also not defined in the Tax Administration Act, and the Short Guide to the Tax Administration Act, 2011, ('the SARS' Guide') contains no guidelines on actions which may constitute dissipations of assets. Based upon the court's decisions in respectively Carmel Trading Company Ltd v Commissioner for South African Revenue Service and Others 70 SATC 1 and Knox, D'Arcy Ltd and Others $v$ Jamieson and Others (4) SA 348 (A), Kruger (2014:31) opines that a dissipation of assets, in the context of taxation, involves the wasting or hiding of assets with the purpose of defeating or blocking the collection of tax debt by the SARS. According to her, it excludes the bona fide sale of such assets at fair value in particular (Kruger, 2014:31).

Williams (2012:6) mentioned that a substantial reason that can cause a court to override an adverse decision for suspension, refers to the case that would arise should there be a significant risk of the dissipation of assets. The risk of dissipation of assets is described by Kotze (2013:27) as the fact that the SARS will consider whether there is an actual risk that the assets of the taxpayer may be reduced, which may jeopardise the collection of the taxes at a later stage. It is therefore submitted that, if the SARS reasonably believes that there is an actual risk as aforementioned, then the SARS can take collection steps before the issuance of the notice of the decision regarding the suspension.

It is also uncertain which assets are being considered when determining the risk of dissipation of assets. Is it all the taxpayer's assets, or only those with a relevant market value that can be considered to cover the taxpayer's debt? Also, what type of assets are considered? An 'asset' is defined in section 1 of the Tax Administration Act to include property of whatever nature, whether moveable or immovable, corporeal or incorporeal, and a right or interest of whatever nature to or in the property. It seems as if the SARS can consider any type of asset in light of this very broad definition.

Although this factor refers to two different types of circumstances that could prevail, and the fact that these two type of circumstances are separated by the word 'or', it is clear that that the senior SARS official should consider both these types of circumstances in order to determine whether one of the two prevail or not. If any one of the two circumstances prevail, it might have a negative impact on the decision of the senior SARS official.

In general, however, it seems that this factor as a whole deals with the consideration of the SARS's credit risk which can be determined through the execution of the SARS' credit risk procedures. Therefore, if the senior SARS official is of the opinion that any type of credit risk exists, it seems as if it might have a negative impact on the outcome of a request. To reduce concerns or uncertainties regarding this factor, it is recommended that its wording be amended to something like 'the recoverability of the amount of disputed tax'. This is also in line with the focus placed by the NCA on the credit risk as discussed in 4.4.

\subsection{2 (b) the compliance history of the taxpayer with SARS;}

It seems as if the uncertainties relating to this factor lie within the phrase 'compliance history'. It is unclear, for example, what type of tax compliance will be considered - only the type being disputed, namely either income tax or VAT, or all the taxes for which the taxpayer is registered at the SARS?

Another matter that is unclear is whether 'compliance' refers to only compliance provisions as stipulated in the Tax Administration Act, or any Act. Regarding the 'history' element of this factor, it is also uncertain how far back in time the SARS will examine the taxpayer's compliance. A 
corollary question is whether the SARS will be lenient in the case of first-time offenders when a taxpayer's compliance history is considered.

Kotze (2013:27) is of the opinion that the following matters regarding the compliance history of taxpayers are among those that will be considered with reference to the request for suspension: regular or serious transgressions in the past, applications for voluntary disclosure relief or amnesty in the past, or any unsuccessful disputes by the taxpayer in the past. Kotze (2013:27) also opines that this does not mean that taxpayers with a poor record will be unsuccessful, but their application might just require more detail.

Kruger (2014:29) states that a suspension of the payment may be more effortlessly granted to a taxpayer with a good compliance history, compared to a non-compliant taxpayer. Kruger (2014:29) is of the opinion that the following factors, to name but a few, might play a role: 'the timeous submission of tax returns, co-operation with the SARS in its investigation of the taxpayer's affairs and payment of taxes due.'

It is clear that these uncertainties contribute to the possible irrelevancy of this factor which is discussed further in 4.5 .

\subsection{3 (c) whether fraud is prima facie involved in the origin of the dispute;}

Rood (2009:44) raised the uncertainty relating to this factor during 2009, when the factors to be considered were introduced for the first time in the relevant sections of the Income Tax and VAT Acts. He submitted that it was unclear whether this section only refers to alleged fraud or to an actual conviction. He suggested that if a mere allegation of fraud is considered, this would be unfair, as taxpayers would not have had the opportunity to defend themselves against the allegation. It is also submitted that it is unclear what the Legislator means by 'the origin of the dispute'. Does this mean that the senior SARS official is of the opinion that fraud is involved in the return submitted by the taxpayer, because this return and the assessment based thereon would have given rise to the dispute and therefore the request?

The words 'prima facie'is Latin for 'at first sight', which means a fact is presumed to be true unless it is disproved or rebutted (Garner, 1999:1209). This means that the SARS is provided with a chance to exercise its discretion to decline a request if, at first sight, it considers fraud to have been involved in the origin of the dispute (Treurnicht, 2015:2). If this is the case and this factor is considered applicable (although all relevant factors should be considered), it seems as if the SARS most probably will ensure that this factor plays a big role in its decision and therefore actually carry a greater weight compared to the other factors considered. The reason for this submission is that fraud is considered a tax offence in terms of section 1 of the Tax Administration Act. Therefore, if applicable, the chances are good that the suspension request will be denied. It is unsure how the SARS will determine whether fraud is prima facie involved in the origin of the dispute in a consistent manner.

\subsection{4 (d) whether payment will result in irreparable hardship to the taxpayer not justified by the prejudice to SARS or the fiscus if the disputed tax is not paid or recovered}

Three uncertainties regarding this factor are identified, namely, how to establish 'irreparable hardship', how to establish 'prejudice to the SARS' and how to weigh them against each other. The last two uncertainties resulted from the amendments in the 2014 TALA. 
No definition for the phrase 'irreparable hardship' exists in the Tax Administration Act. The ordinary meaning of these words requires consideration, as the meaning of the phrase has not yet been considered by the South African courts (Kruger, 2014:32). 'Irreparable' is defined in the OED (2015) as 'not reparable - cannot be rectified or made good (incapable of being repaired)'. The term 'hardship' is defined in the same dictionary as 'a condition which presses unusually hard upon one who has to endure it'.

The word 'financial', which formed part of the initial phrase 'irreparable financial hardship' was removed in terms of section 50 of the TALA. Solomon (2015:par.7) states that the Legislator recognises with this amendment that a taxpayer can suffer irreparable hardship that is not essentially financial, when being forced to make payment before a dispute is resolved. It is however clear that, although any form of hardship will be considered and not only financial hardship, a request for the suspension of payment remains a financial matter. It is therefore questionable whether this amendment was appropriate.

Williams (2012:6) questions the relevance of establishing whether payment will result in irreparable hardship. Dachs (2014:12), however, regards this factor as a key factor to consider. Dachs is concerned that, if taxpayers indicate that the payment of disputed tax will not result in irreparable hardship, the SARS will merely demand that the tax be paid. He also points out that, on the other hand, if taxpayers argue that paying the tax will result in irreparable hardship, the SARS might be concerned that the taxpayers will be unable to make the payment at a later stage, which will also result in the SARS refusing the request for the suspension of payment (Dachs, 2014:12). No guidelines exist regarding the method that the senior SARS official must follow in order to establish 'irreparable hardship' and this raises the concerns of bias, subjectivity and the unequal treatment of taxpayers.

PWC South Africa raised the uncertainty of how the countervailing financial prejudice to the SARS will be measured, seeing that even the largest amount involved in any single tax dispute is a mere drop in the ocean compared to the overall amount of tax collected by the SARS (PWC South Africa, 2015:5). The question asked by PWC South Africa therefore is: Will or can the damage suffered by taxpayers ever be justified by the damage suffered by the SARS? (PWC South Africa, 2015:5). Based on the size of the SARS as an organisation, it seems as if this most probably will never be the case.

This factor in effect now requires that the prejudice to the SARS or the fiscus if the tax is not paid or recovered, must be weighed up against the irreparable hardship that taxpayers will suffer if the tax were paid (Treurnicht, 2015:2). PWC South Africa (2015:5) states that the addition of this requirement to the factor is seen as the most problematic of all the individual factor amendments introduced by the TALA in 2014. According to these authors, the language is questionable, for it submits that it is only in circumstances in which there will be 'irreparable' hardship (and apparently nothing less than 'irreparable' hardship is relevant) that it becomes necessary to balance such hardship against the potential prejudice to the SARS.

PWC South Africa (2015:5) further states that any matching of prejudice between the SARS and taxpayers will be difficult, and even impossible. They explain that in the case of a review, for example, the High Court will ask what weight would match up to the non-financial prejudice to taxpayers of having to dispose of their main residence, rely on public transport to get to work, or move their children from private to public educational institutions so that they can make payment of the disputed tax. They questioned whether it will ever be possible to balance such a lifestyle disadvantage against the purely financial loss that the SARS potentially could experience if the due tax was never paid. In short, according to them, this factor will require a reviewing court to compare apples with oranges (PWC South Africa, 2015:5). Furthermore, PWC South Africa (2015:5) 
is also of the opinion that the current factors as provided for in the legislation, will cause interpretation and application problems to a reviewing court. This being said, combined with the fact that no guidelines exist regarding the method to be followed by the senior SARS official in performing this comparison, underlines the concerns of bias, subjectivity and the unequal treatment of taxpayers. It therefore seems as if the combined uncertainties relating to this factor highlight the possible irrelevancy of this factor.

\subsection{5 (e) whether the taxpayer has tendered adequate security for the payment of the disputed tax and accepting it is in the interest of SARS or the fiscus}

It is clear that the uncertainty relating to this factor is about the meaning of 'adequate security'. How will taxpayers know (or the senior SARS official decide) whether the security tendered for the payment of the disputed tax is considered adequate?

Buttrick (2013:2) notes that, in his and his colleagues' experience, the SARS was willing to allow a suspension where the quantum of taxes were significant provided that taxpayers actually provided adequate security on suitable terms. Kruger (2014:31-32) states that the type of security which might be allowed by the SARS could include securities such as guarantees from holders of shares or the pledge of any assets held by the taxpayer. No formal guidelines or examples which can assist taxpayers to understand what is meant by adequate security have been published by the SARS to date.

Solomon (2015:par.6) highlights that taxpayers are required to not only indicate whether they are able to provide security, but to put it into writing which is a more onerous requirement. It seems that if a taxpayer tenders adequate security, it is doubtful that this factor can negatively influence the discretion exercised by the senior SARS official to grant the suspension of the payment of disputed tax.

Treurnicht (2015:2) submits that the senior SARS official will also be required to consider whether, should the security tendered be accepted, it will be in the interest of the SARS or the fiscus. The words 'and accepting it is in the interest of the SARS or the fiscus', might simply mean that SARS must accept that any adequate security tendered will be in the interest of the SARS or the fiscus. Or, alternatively, it might mean that the security can only be considered for purposes of the request when the security is in the interest of the SARS or the fiscus. This would mean that, even though the taxpayer is able to tender adequate security, it will not be considered in the request for suspension if it is not in the interest of the SARS or the fiscus. These different possible meanings and how to determine what is in the interest of an organisation such as the SARS or the fiscus creates uncertainties.

\subsection{Conclusion}

Based on the aforementioned concerns and uncertainties, the relevance of some of the relevant factors is questionable and it can therefore not be stated that the current relevant factors are indeed the most relevant factors. Treurnicht (2015:3) states that it is clear from the 2014 amendments that it will be harder for taxpayers to convince the SARS to suspend their obligation to pay a disputed amount of tax. If this is true, it places the taxpayer in an unacceptable disadvantaged position. It is therefore considered appropriate to revert to additional sources for possible guidance to determine the most relevant and applicable factors for section 164(3). 


\section{A COMPARISON BETWEEN GRANTING A REPUEST FOR THE SUSPENSION OF PAYMENT IN TERMS OF SECTION 164(3) AND THE GRANTING OF 'CREDIT' IN TERMS OF THE NCA}

\subsection{Introduction}

Section 164(3) of the Tax Administration Act provides that a senior SARS official may 'suspend payment' of the disputed tax. The word 'suspend' is defined in ten different ways in the 0ED depending on the context it is applied to. The most relevant definition from the OED (2015) in the context of section 164(3) is 'to put off to a later time or occasion'. In terms of section 164(3), this means that a taxpayer's obligation to pay its tax debt is temporarily ceased. Subparagraph (a) of the definition of the word 'credit' in section 1 of the NCA states that 'credit' is, inter alia, 'a deferral of payment of money owed to a person, or a promise to defer such a payment'. It therefore seems that there might be a connection between the words 'defer' and 'suspend'. This is investigated in order to determine the relationship between granting a request to 'suspend' a payment of disputed tax in terms of section 164(3), and a 'credit agreement' to 'defer a payment' in terms of the NCA.

\subsection{The relationship between 'defer' and 'suspend'}

According to Garner (1999:1469), the verb 'suspend' is defined as 'to interrupt; postpone; defer'. This clearly indicates that the two words, 'suspend' and 'defer', have a similar meaning. Burton's (2007:561) Legal Thesaurus also makes an explicit connection between the words 'defer' and 'suspend', where 'defer' is referred to as an alternative word for 'suspend' (Burton, 2007:561) and 'suspend' is also noted as a synonym for 'defer' (Burton, 2007:153).

It is therefore clear that these two words are synonyms and can therefore be used as substitutes for each other. According to the common law maxim 'Eiusdem generis', courts should interpret terms of the same kind in a similar manner. Hence, it is clear that to 'suspend a payment' in terms of section 164(3) can be equated to the provision of 'credit' (being a deferral of payment) in terms of the NCA. The NCA can therefore be used as an additional resource to identify possible guidance regarding section $164(3)$.

\subsection{The relationship between a 'credit agreement' to defer a payment in terms of the NCA and granting a request for suspension in terms of section 164(3)}

Section 4(1) (a) (iii) of the NCA states that it applies, amongst others, to every 'credit agreement' between parties dealing at arm's length and made within, or having an effect within, the Republic, except a credit agreement in terms of which the consumer is an organ of state. If granting a request for suspension in terms of section 164(3) meets the definition of a 'credit agreement', the NCA can therefore be used as a guidance.

The two parties involved in a request for suspension in terms of section 164(3) are the taxpayer and the senior SARS official, therefore meeting the requirement of two parties dealing at arm's length in terms of the NCA. It is clear that, in most cases, the request will be submitted in South Africa and it must therefore now be determined whether granting a request for the suspension of the payment of disputed tax can be seen as a 'credit agreement' in terms of the NCA, and whether 
the aforementioned exception is applicable or not. Although the SARS is an organ of state (South African Revenue Service Act, 34 of 1997), the 'consumer' in terms of the request is the taxpayer and not the SARS. The aforementioned exception referred to in section $4(1)(a)$ (iii) of the NCA is therefore not applicable.

The word 'agreement' in the term 'credit agreement' is defined in section 1 of the NCA as 'an arrangement or understanding between or among two or more parties, which purports to establish a relationship in law between those parties.' It seems that once a taxpayer requests a senior SARS official to suspend the payment of disputed tax, an understanding is created between the taxpayer and the senior SARS official with the intention to establish a relationship between these two parties in terms of the Tax Administration Act. It is therefore submitted that a request for suspension constitutes an 'agreement' in terms of the NCA.

A 'credit agreement' is defined in section 1 of the NCA as an agreement that meets all the criteria as set out in section 8 of the NCA. The section 8 criteria relevant to this discussion is contained in section $8(1)(b)$ of the NCA which states that an agreement constitutes a credit agreement for the purposes of this Act if it is, inter alia, a 'credit transaction', as described in section 8(4). In terms of section $8(4)(f)$ an agreement constitutes a credit transaction if it is 'any other agreement, other than a credit facility or credit guarantee, in terms of which payment of an amount owed by one person to another is deferred, and any charge, fee or interest is payable to the credit provider in respect of (i) the agreement; or (ii) the amount that has been deferred'.

Section $8(4)(f)$ of the NCA therefore firstly requires that there must be an agreement in terms of which the payment of an amount owed is deferred. A taxpayer requests, in terms of section 164(3), the senior SARS official to suspend the payment of the amount of disputed tax owed to the SARS. In light of the words 'defer' and 'suspend' being synonyms granting a request to suspend payment in terms of section 164(3) is therefore similar to an agreement in terms of which the payment of an amount owed is deferred.

The second required element of a credit transaction in terms of section $8(4)(f)$ of the NCA entails that any charge, fee or interest must be payable to the credit provider in respect of the amount that has been deferred. It must therefore be established whether interest is payable on the amount of disputed tax if the payment thereof is suspended in terms of section 164(3), and whether the SARS can be seen as a 'credit provider' in this situation.

The notice of assessment issued by the SARS must, in terms of section 96(1)( $f$ ) of the Tax Administration Act, contain the date for paying the amount of tax assessed. The obligation to pay this tax by that date is not suspended by an objection or appeal (section 164(1) of the Tax Administration Act). However, if a taxpayer intends to dispute (meaning that the taxpayer intends to object against the assessment) or dispute the liability to pay such tax under Chapter 9 of the Tax Administration Act, a request for the suspension of payment can be made in terms of section 164(2) of the Tax Administration Act. Such a request for suspension is therefore merely a step prior to an objection against an assessment.

Section 187 of the Tax Administration Act contains the provisions regarding interest payable, but since the date of commencement of this section must still be proclaimed, interest is still imposed in terms of specific provisions of the relevant tax Acts. Section 89(2) of the Income Tax Act determines that, if the taxpayer fails to pay any tax in full by the date in the notice of assessment, interest shall be payable unless the Commissioner grants an extension and otherwise directs. Section 164(7)(a) of the Tax Administration Act also states that interest remains payable on amounts short paid even if an assessment is altered after an objection or appeal. 
According to the SARS' Guide (2013:59), interest will also continue to accrue on the unpaid amount even if a taxpayer's payment obligation is suspended in terms of a review application against an adverse decision of a request in terms of section 164(3). Interest is therefore payable on the disputed amount of tax whether the payment thereof has been suspended in terms of section 164(3) or not, thereby meeting the interest requirement of section $8(4)(f)$ of the NCA.

In order to determine whether the SARS can be seen as a 'credit provider', the definition of the term in section 1 of the NCA must be considered. This definition lists nine specific persons including, in subparagraph $(h)$, 'the party who advances money or credit to another under any other credit agreement'.

When granting a request for the suspension of the payment of disputed tax, the SARS grants 'credit' to the taxpayer, based on both their 'agreement' (understanding) in terms of the request and the relationship between the words 'defer' and 'suspend'. It is therefore concluded that the SARS can, in this case, be seen as a 'credit provider' in terms of the NCA according to subparagraph $(h)$ of the definition of the term.

It is therefore concluded that granting a request for the suspension of the payment of disputed tax can be equated with a credit transaction in terms of section $8(4)(f)$ of the NCA and is therefore a 'credit agreement' as defined in section $8(4)(f)$ of the NCA. In light of the aforementioned, the other relevant provisions of the NCA could prove to provide guidance regarding the relevancy of the relevant factors taken into account by the senior SARS official.

\subsection{The factors to be considered or process to be followed when credit is provided or refused in terms of the NCA}

In terms of section 60(1) of the NCA, any adult natural person and every juristic person or association of persons has a right to apply to a credit provider for credit. Scholtz (2015:par.6.2.2) emphasises that section 60(1) provides for the right to apply for credit, and not for a right for the credit to be granted. One of the most important statutory duties of credit providers is that the credit provider must perform a credit assessment before entering into a credit agreement with a prospective consumer (0tto, 2012:par.34.1). The reason for this statutory duty is based on one of the main purposes of the NCA, namely to discourage the granting of reckless credit (Scholtz, 2015:par.6.5.4).

A credit agreement is seen as 'reckless' in terms of section 80 of the NCA if, at the time that the agreement was made, the credit provider failed to conduct an assessment as required by section $81(2)$, or the credit provider entered into the credit agreement with the consumer, despite the fact the consumer did not generally understand the risks, costs or obligations under the proposed credit agreement; or the information available to the credit provider indicated that entering into a credit agreement would make the consumer over-indebted.

Section 81(2) of the NCA specifies that, before entering into a credit agreement, the credit provider must first take reasonable steps to assess -

(a) the proposed consumer's -

(i) general understanding and appreciation of the risks and costs of the proposed credit, and of the rights and obligations of a consumer under a credit agreement;

(ii) debt re-payment history as a consumer under credit agreements; 
(iii) existing financial means, prospects and obligations; and

(b) whether there is a reasonable basis to conclude that any commercial purpose may prove to be successful, if the consumer has such a purpose for applying for that credit agreement.

The NCA does not contain detailed provisions specifying exactly how the assessment must be executed, apart from the broad considerations in the provision above (Scholtz, 2015:par.11.4.2). As long as the assessment mechanisms used by credit providers are fair and objective, they may use their own means of evaluation (section 82(1) of the NCA). As part of the assessment, credit providers can consider making use of the information kept by the National Credit Bureau to obtain information on the consumer. 'Consumer credit information' is defined in section 70(1) of the NCA as:

(a) a person's credit history, including applications for credit, credit agreements to which the person is or has been a party, pattern of payment or default under any such credit agreements, debt re-arrangement in terms of this Act, incidence of enforcement actions with respect to any such credit agreement, the circumstances of termination of any such credit agreement, and related matters;

(b) a person's financial history, including the person's past and current income, assets and debts, and other matters within the scope of that person's financial means, prospects and obligations, as defined in section 78(3), and related matters;

(c) a person's education, employment, career, professional or business history, including the circumstances of termination of any employment, career, professional or business relationship, and related matters; or

(d) a person's identity, including the person's name, date of birth, identity number, marital status and family relationships, past and current addresses and other contact details, and related matters.

Section 81 (1) of the NCA also requires that, while an application for a credit agreement is being considered by a credit provider, the prospective consumer must answer fully and truthfully any requests for information made by the credit provider.

The decision whether to grant credit in terms of the NCA therefore entails an in-depth process to be followed. This is done in terms of a credit assessment, where specific factors or steps need to be assessed on a reasonable basis and can also include the consideration of consumer credit information. It is, however, clear that the consumer's credit history and debt repayment history, as well as his or her financial history, means and obligations, play an important role in this assessment. Although broad guidelines are stipulated by the NCA, credit providers are still permitted to use their own means of evaluation as long as these are fair and objective and credit is not granted recklessly. The prospective consumer and the credit provider also needs to collaborate with one another during the period of consideration. 


\subsection{A comparison between the factors or process to be followed in terms of section 164(3) and the NCA}

The following differences and similarities between the granting of a request for the suspension of the payment of disputed tax and credit-granting in terms of the NCA is of importance:

\subsubsection{Focus points}

As seen from sections 81(2) and 70(1) of the NCA, the credit assessment focusses on the credit provider's credit risk with reference to the prospective consumer's credit history and financial history. The current relevant factors in section 164(3) have different focus points.

In a media release (2015: par 2) issued by the SARS on 1 April 2015 relating to the 2014/2015 fiscal year, a $9.6 \%$ growth in total revenue (R986.4 billion) from 2013/2014 was announced. In this media release it was also stated that the reason for this revenue performance, was due to an extraordinary drive by the SARS on compliance improvement, which compensated for the revenue collection shortfall caused by a slowing economy (2015:par.2). This confirms the SARS' focus on revenue collections and a lower credit risk. Therefore one would expect the SARS to focus on matters or considerations relating to this concern, when considering a request for the suspension of the payment of disputed tax.

It is clear that that three of the current five relevant factors (being factors (a), (d) and (e) as discussed in 3) in section 164(3), focus on matters relating to the revenue collection concern of the SARS. However, taking 'the compliance history of the taxpayer with SARS' (relevant factor (b)) into account as a factor seems unrelated to the concern of revenue collection. It is a regulatory matter in the sense that it includes, for example, the consideration of whether the taxpayer has submitted its returns on an annual basis and within the required time period. It seems that the SARS should rather consider the 'payment' history of the taxpayer as a relevant factor, in order to determine if the taxpayer pays its amounts owed to the SARS on a regular basis. This will add more value to address the revenue collection concern and is in line with the NCA.

\subsubsection{Additional matters for possible consideration by the senior SARS official}

With reference to the reasonable steps provided for in section 81(2) of the NCA, the following additional factors are recommended for consideration in terms of section 164(3):

- The senior SARS official must establish how many previous requests for the suspension of the payment of disputed tax the taxpayer has submitted, including the results of such requests. These details should be easily accessible from the SARS' database. This will provide the senior SARS official with an indication as to whether the taxpayer is familiar with the request process and has made all the payments in respect of disputed tax which have previously been suspended on request.

- The senior SARS official must determine the current financial means, prospects and obligations of the taxpayer. This will include the consideration of the taxpayer's cash position according to its bank statements, the taxpayer's fixed monthly income, the taxpayer's assets and debts, etc. Such determination is deemed to be relevant because it will assist the senior SARS official in determining whether the taxpayer is financially secure and will be able to pay the disputed tax should the outcome of the dispute be in favour of the SARS. This will ensure that the SARS eliminates taking any credit risk by 
granting the request for suspension. It is noted in SARS' 2013/14-2017/18 strategic plan that the SARS is considering to collaborate with credit bureaus to gain third party information on taxpayers (South African Revenue Services: Strategic Plan, 2013:44). The SARS should consider the use of such collaboration in gaining information for this purpose.

- The senior SARS official should assess the taxpayer's general understanding of the relevant provisions impacting the request, namely those of subsections (4) to (7) of section 164 of the Tax Administration Act. This could contribute to that both parties understand their rights and obligations in terms of a request for the suspension of the payment of disputed tax which could facilitate better relations between the parties and prevent the possibility that granting a suspension will make the taxpayer overindebted.

\subsubsection{The ambit and relevancy of the factors or reasonable steps during the process of consideration}

A general difference noted is the fact that the factors and steps listed in the NCA are considerably less and to the point compared to the specified list of relevant factors in terms of section 164(3). It is therefore submitted that the execution of these steps most probably result in fewer uncertainties or concerns, compared to the numerous concerns and uncertainties relating to the factors in section 164(3), as previously discussed.

Compared to the inclusion of the phrase 'relevant factors, including' in section 164(3), it is also noticeable that the reasonable steps in terms of the NCA do not include any specific reference to for example, 'any other relevant matters' to be assessed as part of the required credit assessment. The exclusion thereof keeps the credit assessment in terms of the NCA to the point and should contribute to quicker responses from credit providers.

Limited information is available regarding the factors considered and the process followed by the SARS. It is, however, clear that if the aforementioned means of evaluation used by the SARS is fair and objective as indicated by the NCA in terms of section $82(1)$, credit will not be granted recklessly.

It is suggested that the specified list of relevant factors be revised and updated to include only the most relevant factors as recommended and discussed above. The SARS should then rather, after taking into account only these factors, request the taxpayer to submit any identified relevant material needed to finalise the decision. Such a process is similar to section 81 (1) of the NCA which requires the prospective consumer to answer fully and truthfully any requests for information made by the credit provider, while an application for a credit agreement is being considered.

Should a taxpayer not give his or her co-operation in this regard, it could possibly impact the process negatively. Such a request for material might, however, impact the timing of a response but it will reduce the possibility of unnecessary paperwork due to the current unresolved concerns and uncertainties taxpayers experience with this process. The taxpayer would also be informed in detail of what the SARS requires. The suggestion should therefore have a positive influence overall. 


\subsubsection{Acting recklessly}

The senior SARS official are required to carry out its statutory duties in terms of section 6 of the Tax Administration Act. The senior SARS official therefore cannot grant requests which might result in an increase of the SARS's credit risk and thereby reducing the possibility of revenue collection. This is similar to section 80 of the NCA, which discourages the granting of reckless credit.

\subsection{Conclusion}

Granting requests for the suspension of the payment of disputed tax can have a negative impact on the SARS' revenue collection and credit risk. Croome (2009:12) opines that, although a taxpayer may have an arguable case and can satisfy the relevant factors, the SARS will insist on the payment of the tax in dispute due to the economic conditions and shortfalls in revenue collections. Buttrick (2013:2) highlights that any decision to not grant a suspension of payment of tax pending a dispute in respect of a single taxpayer, needs to be weighed against the larger public's need for appropriate and timeous collection of funds for the fiscus.

\section{SUMMARY, CONCLUSIONS AND RECOMMENDATIONS}

In light of the existing concerns and uncertainties regarding the relevant factors, section 164(3) of the Tax Administration Act was compared to a statute outside the sphere of tax law, namely the NCA. The comparison was performed to establish whether the current relevant factors are the most relevant factors and to identify other possible enhancements as recommendations, which can simplify the process of a request for the suspension of the payment of disputed tax.

The conclusion is made that the Tax Administration Act provisions do contain some similarities to the relevant NCA provisions, but the provisions of the Tax Administration Act are broader and less to the point, which in return creates concerns and uncertainties. It is concluded that the current factors listed are not necessarily the most relevant and applicable ones to consider regarding a request for the suspension of the payment of disputed tax.

It is suggested that the SARS should strongly consider to revise the specified list and the wording of the relevant factors as suggested to ensure that the factors focus on the matters that are most relevant in this regard, namely to enhance revenue collections and to minimise any risk that the SARS will not receive the disputed tax debt owed to them if the payment thereof is suspended. The recommended additional facts to be considered, as derived from the process followed by the NCA, will contribute to a less complicated process and reduce the concerns and uncertainties relating to the current relevant factors. It is therefore recommended that the SARS should strongly consider to bring the relevant factors in section 164(3) in line with the equivalent provisions found in the NCA to ensure clarity and a simplified process. This could facilitate the process regarding future requests for the suspension of disputed tax by taxpayers and endorse the SARS' focus on low risk revenue collection.

\section{LIST OF REFERENCES}

Acts see South Africa. 
Burton, W.C. (2007). Burton's Legal Thesaurus Fourth Edition. New York: McGraw-Hill.

Buttrick, D. (2013). Whether wrong or right, pay now. Moneyweb's TAX BREAKS, May, pp. 1-3.

Carmel Trading Company Ltd v Commissioner for South African Revenue Service and Others 200770 SATC 1.

Croome, B. (2009). Court decision gives some hope to objecting taxpayers. Business Day, 11 August, p. 12.

Dachs, P. (2014). Pay now argue later. Tax Professional, 21 July, pp. 10-12.

Garner, B.A. (1999). Black's Law Dictionary Seventh Edition. West Group.

Knox, D'Arcy Ltd and Others v Jamieson and Others 1996 (4) SA 348 (A).

Kotze, D. (2013). Pay now argue later. TaxTalk, Jan/Feb, p. 27.

Kruger, L. (2014). Pay now, argue later new rules for the suspension of payment. Business Tax \& Company Law Quarterly, 5(2), pp. 27 - 35.

Otto, J.M. (2012). The National Credit Act explained. Electronic Edition. Updated: 2012. LexisNexis. Available: http://www.mylexisnexis.co.za.ez.sun.ac.za/Index.aspx\# (Accessed on 12 August 2015).

Oxford English Dictionary. (2015). Updated: June 2015. Oxford University Press. Available: http://www.oed.com/ (Accessed on 1 September 2015).

PWC South Africa. (2015). Tax Administration Laws Amendment Bill (B14 of 2014) will effect amendments to the Tax Administration Act No. 28 of 2011. TaxTalk. Available:

http://www.taxtalk.co.za/tax-administration-laws-amendment-bill-bl4-of-2014-will-effectamendments-to-the-taa/ (Accessed on 3 September 2015).

Rood, L. (2009). Betaal nou, kla later. FinWeek, 13 August, p. 44.

Scholtz, J.W. (2015). Guide to the National Credit Act. Electronic Edition. Updated: June 2015. LexisNexis. Available: http://www.mylexisnexis.co.za.ez.sun.ac.za/Index.aspx\# (Accessed on 12 August 2015).

Solomon, T. (2015). "pay now, argue later' - recent amendments to section 164 of the Tax Administration Act No. 28 of 2011. Available: https://www.ensafrica.com/news/pay-now-arguelater-recent-amendments-to-section-164-of-the-TaxAdministration? Id $=17728$ STitle=tax\%20ENSight (Accessed on 15 August 2015).

South Africa. (1962). Income Tax Act, No. 58 of 1962. Pretoria: Government Printer.

South Africa. (1997). South African Revenue Service Act, No. 34 of 1997. Pretoria: Government Printer.

South Africa. (2006). National Credit Act, No.34 of 2005.

South Africa. (2011). Tax Administration Act, No. 28 of 2011. Pretoria: Government Printer.

South Africa. (2015). Tax Administration Laws Amendment Act, No. 44 of 2014. Cape Town: Government Printer.

South African Revenue Service. (2013). Short Guide to the Tax Administration Act, 2011 (Act No. 28 of 2011) (version 2). 5 June 2013.

South African Revenue Service. (2013). Strategic Plan 2013/14-2017/18. Available: http://www.sars.gov.za/AllDocs/SARSEntDoclib/Ent/SARS-Strat-10\%20\%20SARS\%20Strategic\%20Plan\%202013-14\%20to\%202017-18.pdf (Accessed on 12 August 2015). 
South African Revenue Service. (2015). Media Release: Preliminary outcomes of Revenue collection for the 2014-2105 fiscal year. Pretoria.

Treurnicht, M. (2015). Changes to criteria considered by SARS when suspending payment of tax. Tax Alert. 30 January 2015, pp. 2-3.

Williams, RC. (2012). Unresolved aspects of the 'pay now later' rule. January Synopsis, pp. 4-6. 